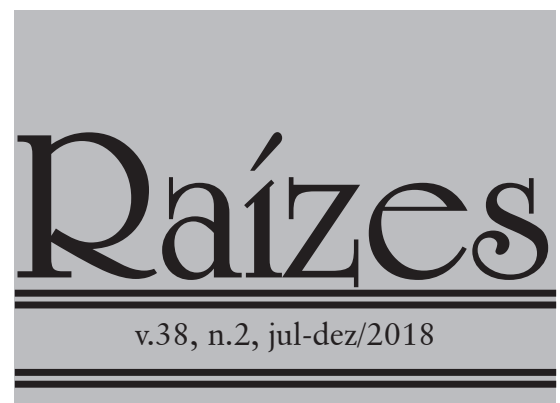

\title{
“POLÍTICA E NEGOCIAÇÕES” NOS TRILHOS DA CONVIVÊNCIA COM O SEMIÁRIDO
}

Shana Sampaio Sieber ${ }^{1}$, Ramonildes Alves Gomes ${ }^{2}$

\begin{abstract}
RESUMO
O presente artigo busca refletir sobre o processo de implementação do Plano Municipal de Convivência com o Semiárido, no município de Serra Talhada - PE, problematizando a disputa de significados atribuídos ao discurso da Convivência com o Semiárido pela Sociedade Civil, através das Organizações Não Governamentais (ONGs), e pelo Estado, por meio do poder público. A análise desse processo nos leva a questionar o protagonismo da sociedade civil ante o contexto de proximidade desta com o Estado, produzindo uma espécie de Confluência Perversa. O exercício metodológico privilegiou a observação de reuniões, a análise de documentos e a realização de entrevistas. As evidências dão conta de que a Convivência, enquanto prática política, foi reduzida ao acesso a programas e políticas governamentais, à competição para a obtenção de cargos públicos e ao oportunismo político partidário, colocando em questão o potencial transformador da sociedade civil.

Palavras-chave: Convivência com o Semiárido; Sociedade Civil; Estado; Políticas Públicas.
\end{abstract}

\section{"POLITICS AND NEGOTIATIONS" IN THE TRAILS OF THE COEXISTENCE WITH THE SEMIÁRID}

\begin{abstract}
The present article has as starting point to reflect on the actions of implementation of the $\mathrm{Mu}$ nicipal Plan of Coexistence with the Semi-Arid, in the municipality of Serra Talhada (Sertão de Pernambuco), through a narrative of coexistence that distances itself from the sense of Non-Governmental Organizations). The objective is to problematize the dialogue between civil society and the State, from the assumption that the discourse of the coexistence with the semiarid is announced by the protagonism of the civil society. In practice, however, it reproduces a perverse confluence through the discourse of the State as a space of convergent interests. The methodological exercise privileged the observation of meetings, the analysis of documents and the interviews with nine managers who acted, promoting actions of coexistence. The results showed that the coexistence with the semiarid developed in the municipality of Serra Talhada under a political practice reduced to access to the government programs and policies, competition for public office and party-political opportunism, calling into question the position political and combative nature of some sectors of civil society.

Key words: Living with the Semi-Arid; Civil Society; State; Public Policy.

${ }^{1}$ Doutora em Ciências Sociais. PPGCS/Universidade Federal de Campina Grande. E-mail: shanasieber@yahoo.com.br ${ }^{2}$ Professora e Pesquisadora no Programa de Pós Graduação em Ciências Sociais, Universidade Federal de Campina Grande. E-mail: rnildes@hotmail.com
\end{abstract}




\section{INTRODUÇÃO}

O objetivo desse artigo é refletir sobre a Convivência com o Semiárido, e foi no contexto de mais um longo ciclo de estiagem no semiárido nordestino, com a seca que se iniciou no ano de 2012, que buscamos analisar as negociações para o desenvolvimento das ações planejadas em torno da narrativa da convivência com o semiárido. Privilegiamos, como recorte, o processo de implementação do Plano Municipal de Convivência com o Semiárido, no município de Serra Talhada (Sertão de Pernambuco), a partir da relação entre a sociedade civil e o Estado.

O município de Serra Talhada ${ }^{3}$ (PE) se constitui enquanto uma referência empírica interessante, quando se torna palco de um processo de sindicalização rural importante no Estado de Pernambuco, respaldado por movimentos de luta contra as políticas de combate à seca , apoiado pela Igreja Católica, representada pela Diocese de Afogados da Ingazeira (PE). Nesse contexto, o discurso da convivência era orientado para a desconstrução da seca como obra de Deus, passando a ser encarada como um fenômeno natural que demandava soluções racionalizadas.

Atores importantes para o município de Serra Talhada emergiram desse movimento, contando com o apoio da Igreja católica para a reprodução de lideranças sindicais e organizações não governamentais (ONGs), capazes de colocar em discussão alternativas aos problemas da seca, ao mesmo tempo que reforçavam as críticas às políticas de combate à seca, até então dominantes, operando no diálogo entre a sociedade civil e o Estado.

Saído do movimento social, na condição de Agente Pastoral da Ação Católica Rural (ACR), Manoel Santos se destaca no município de Serra Talhada como liderança Sindical, assumindo a presidência do Sindicato dos Trabalhadores Rurais de Serra Talhada (SRT- 1975), na década de 1980. A partir daí, esse personagem atua em diferentes espaços políticos, desde a presidência da Federação dos Trabalhadores da Agricultura do Estado de Pernambuco (FETAPE), até a Confederação Nacional dos Trabalhadores na Agricultura (CONTAG), passando pela secretaria rural da Central Única dos Trabalhadores (CUT) e pelo Partido dos Trabalhadores (PT); e enquanto deputado estadual, tendo como pauta o fortalecimento da agricultura familiar, da agroecologia, da reforma agrária e a defesa dos direitos das comunidades quilombolas, indígenas e tradicionais. No setor das ONGs, temos como referência o Centro de Educação Comunitária Rural (CECOR). Fundado em 1994, o CECOR surgiu de um Projeto da Diocese de Afogados da Ingazeira - Projeto de Educação Comunitária Rural (PECOR) que atuava na região, desde os anos 80 , com as chamadas tecnologias alternativas, angariando recursos da Cooperação Internacional.

No município de Serra Talhada, o discurso do protagonismo da sociedade civil ${ }^{4}$, sustentado pela trajetória de luta dos movimentos sociais e das organizações não governamentais (ONGs), é mobilizado para a construção do Plano Municipal de Convivência com o Semiárido. Esse discurso transita entre o engajamento político da sociedade civil e a sua incorporação pelo Estado. Desse modo, surge uma relação que denominamos de confluência perversa. O discurso da convivência é enunciado por uma sociedade civil que se pensa ativa e propositiva, contudo,

\footnotetext{
${ }^{3}$ Diante da seca que perdurou cinco anos (1979-1984), as insatisfações dos trabalhadores rurais frente às políticas de combate à seca amadureciam. A exclusão de mulheres no alistamento das Frentes de Emergência, a expulsão dos trabalhadores das fazendas, os maus tratos dos trabalhadores nas Frentes de Emergência, a desativação do Programa de Emergência, a inadimplência do Programa de Cesta Básica, o descumprimento dos acordos para a construção de barragens. Este era um cenário de fome e que marcou a trajetória dos movimentos sociais no município de Serra Talhada, a exemplo dos saques que aconteceram na região, da luta das mulheres por espaços nos sindicatos, da luta do Travessão de Caiçarinha da Penha contra grandes proprietários, criadores de gado e a luta dos trabalhadores rurais da Barragem de Serrinha. Estes momentos evidenciavam a indignação da população ante às ações e omissões do governo, lideradas pelo Sindicato dos Trabalhadores Rurais de Serra Talhada e pela FETAPE, com apoio da Igreja Católica.
} 
para implementar as ações da convivência, setores da sociedade civil se aproximam do Estado, fazendo convergir diversos interesses e construindo uma pauta de programas e ações comuns.

Adotamos a categoria confluência perversa com base na definição adotada por Evelina Dagnino (2004a, 2004b), para explicar a relação entre dois projetos políticos distintos, que tem como porta vozes atores em disputa. De um lado, temos um projeto estratégico do Estado para implementação do ajuste neoliberal, reforçando um Estado mínimo que se isenta do papel de garantidor de direitos, através da transferência de suas responsabilidades para a sociedade civil. De outro lado, um projeto democratizante e participativo que emerge a partir das crises dos regimes autoritários e dos esforços nacionais de aprofundamento democrático.

Desde a promulgação da Constituição de 1988 a relação entre Estado e ONGs se constitui em um campo minado de interlocução entre projetos distintos, que aparentemente reivindicam os mesmos interesses: uma sociedade civil ativa e propositiva. A "perversidade" é assumida enquanto fenômeno, cujas consequências contrariam a aparência, tendo como consequência um projeto distinto do originalmente pensado, servindo aos objetivos do projeto que lhe é antagônico. Como exemplo, tem-se as políticas de combate à seca, que consistiam em projetos de modernização, voltados para a construção de açudes, barragens e para a grande irrigação (Sieber; Gomes, 2016).

As narrativas sobre a Convivência com o Semiárido vão além do sentido e das ações difundidas pela Articulação do Semiárido (ASA) e por outras Organizações Não Governamentais (ONGs), que buscam construir conhecimentos e tecnologias acerca da convivência com o semiárido, respeitando e valorizando o saber dos agricultores e a sustentabilidade do ambiente. A narrativa que informa sobre a convivência tem seus antecedentes na luta dos movimentos sociais frente ao Estado, tendo como contraponto as políticas de combate à seca. No entanto, é no diálogo e na disputa para implementação das ações que materializam a convivência com o semiárido, sob a forma específica de um Plano Municipal, que se dá a apropriação pelo próprio Estado dos princípios e métodos que o distinguem da sociedade civil.

No percurso da pesquisa, participamos como observadores de eventos, tendo como referência as reuniões do Conselho Municipal de Desenvolvimento Rural Sustentável (CMDRS) e o IV Seminário NEPPAS: caminhos, olhares e práticas da agroecologia nos sertões de Pernambuco", no qual pôde ser observada a fala da gestora da Secretaria Municipal, na Plenária sobre o Plano Municipal de Convivência com o Semiárido.

Além do levantamento bibliográfico, que foi importante para compreender a perspectiva ontológica da convivência com o semiárido e suas estratégias, enquanto projeto político, também nos apoiamos em documentos históricos, tendo como orientação o I Seminário Pernambucano, Seca: Implicações políticas e formas de enfrentamento (1990), o Dossiê Fórum Seca (1991) e o Relatório Histórico do Fórum Seca (1989 a 1996).

As entrevistas foram feitas com atores que participaram da construção do Plano Municipal de Convivência com o Semiárido, utilizando um roteiro semiestruturado com perguntas abertas conduzidas junto aos gestores das seguintes instituições: Secretaria da Agricultura familiar de Serra Talhada, FETAPE, ASA, Universidade Federal Rural de Pernambuco, CECOR, Centro Sabiá e Prefeitura Municipal de Serra Talhada. A imersão no universo das ONGs nos conduziu ao Fórum Seca (1989 e 1997) revelando acontecimentos fundamentais para a compreensão do espaço político disputado pela convivência, a exemplo da ocupação da SUDENE e do Fórum

\footnotetext{
${ }^{4}$ Assumimos como definições de sociedade civil e de Estado, concepções cujos os significados foram gestados pelos atores no espaço social da pesquisa. Assim, entendemos como sociedade civil todas as formas sociais que se diferenciam do Estado: ONGs, movimentos sociais, entidades do chamado Terceiro Setor, fóruns, conselhos municipais, sindicatos, pesquisadores e agricultores. Por Estado, compreende-se os entes federativos que compõem o governo federal, estadual e municipal, os quais atuam na gestão, controle e organização de um território e da população, através do exercício da burocracia.
} 
Nordeste, que evidenciou a centralidade do município de Serra Talhada no estado de Pernambuco, no contexto de uma disputa partidária entre atores políticos como Lula e Collor.

\title{
2. A CONVIVÊNCIA COM O SEMIÁRIDO E SEUS ANTECEDENTES HISTÓRICOS
}

A história da convivência com o semiárido passa oficialmente pelo episódio da ocupação da SUDENE, em 1993, como ação de referência de uma demanda da sociedade civil que chegava ao Estado pela via da mobilização, requerendo "Ações Permanentes para o Desenvolvimento do Nordeste/Semiárido Brasileiro". Para a convivência com o semiárido este movimento traria um significado emblemático para a sociedade civil (Diniz; Piraux, 2011a).

Tendo a ASA se consolidado enquanto articulação no Fórum Paralelo da Sociedade Civil, durante a $3^{\text {a }}$ Conferência das Partes da Convenção de Combate à Desertificação e à Seca (COP3), em 1999, é elaborado um documento que sistematiza o entendimento das organizações e dos movimentos sociais em torno do semiárido e da convivência com ele, em substituição às ações de combate à seca, com a Declaração do Semiárido (1999). Ante uma conjuntura política favorável, as ações da convivência são postas em prática a partir do Governo Lula, revelando um "experimentalismo institucional" (Diniz; Piraux, 2011b). Com a implantação do "Programa de Formação e Mobilização Social para a Convivência com o Semiárido: Um Milhão de Cisternas Rurais” (P1MC), em 2003, o diálogo entre a sociedade civil e o Estado se tornaria oficial.

O manto da Convivência com o Semiárido influenciou programas governamentais, a exemplo do destaque que recebeu no programa "Fome Zero", com o "Sede Zero". Aqui, a convivência legitimava um diálogo com o Estado para além das reivindicações mobilizatórias, instituindo um campo no qual a distinção entre o Estado e a sociedade civil se tornava contraditória, mas suficientemente sedutora, destacando constantemente o protagonismo dos movimentos sociais frente ao Estado (Diniz, 2007):

\begin{abstract}
Nós da sociedade civil, mobilizada desde o mês de agosto através da Articulação Semiárido (ASA); nós que, nos últimos meses, reunimos centenas de entidades para discutir propostas de desenvolvimento sustentável para o Semiárido; nós dos Sindicatos de Trabalhadores Rurais, das Entidades Ambientalistas, das Organizações Não-Governamentais, das Igrejas Cristãs, das Agências de Cooperação Internacional, das Associações e Cooperativas, dos Movimentos de Mulheres, das Universidades; nós que vivemos e trabalhamos no Semiárido; nós que pesquisamos, apoiamos e financiamos projetos no Sertão e no Agreste nordestinos, queremos, antes de mais nada, lançar um grito que não temos sequer o direito de reprimir: queremos uma política adequada ao semiárido! (Declaração do Semiárido, 1999).
\end{abstract}

Entre 1989 e 1997, o Fórum Seca representaria um esforço de articulação de âmbito estadual capaz de mediar a força da sociedade civil organizada com os processos de sindicalização rural na direção do Estado, reivindicando ações significativas para o que se tem hoje sistematizado como convivência com o semiárido. O Ato Público de lançamento do Fórum Seca foi realizado no município de Serra Talhada, em 1991. Esse evento trouxe à tona muito mais do que a representação do município nas discussões sobre a convivência com o semiárido; trouxe argumentos capazes de recompor um campo de luta dos movimentos sociais frente ao Estado. De um discurso que pretendia se opor a um modelo de produção baseado na modernização tecnológica que beneficiava grandes proprietários e fomentava as disputas eleitorais, ele 
se manifestaria em uma lógica de articulação modernizada que inaugurava um espaço público não-estatal na construção de um projeto político, em oposição às políticas do governo Collor.

O discurso do Fórum Seca buscou tanto qualificar a crítica ao Estado, quanto pressionar uma mudança nos rumos da sua ação, através de um Estado entendido como governo, marcado por uma trajetória autoritária e manipuladora, baseada na exploração do povo em época de seca; um Estado neoliberal que pretendia transferir suas responsabilidades para a sociedade civil (Dagnino; Teixeira, 2014). O Estado, portanto, seria um espaço de interesses eleitoreiros orientado para o grande latifúndio. Já a sociedade civil seria protagonista de uma alternativa à problemática da seca, capaz de disputar e executar ações concretas voltadas aos mais empobrecidos.

O flagelo da seca é sentido pelos trabalhadores rurais já há séculos. As intervenções do Estado (federal, estadual e municipal), mais do que um paliativo, têm proporcionado a consolidação da "indústria da seca" e a dependência dos agricultores aos políticos fisiológicos. Por outro lado, o Movimento Sindical, as assessorias populares, os pesquisadores, têm acumulado experiências alternativas e análises que ainda estão dispersas pela insuficiente articulação entre esses setores. A motivação número um para a construção de um Fórum Alternativo à Problemática da Seca é reunir esse potencial de luta e conhecimento para tornar real um Projeto de Enfrentamento às Implicações da Seca, assumido por um corpo legítimo e representativo das organizações dos trabalhadores rurais e de suas assessorias. Após 113 anos de frentes de emergência ineficazes, eleitoreiras e enriquecedoras dos latifúndios, é imprescindível que os setores populares, organizados em entidades classistas e de assessoria, definam uma estratégia de atuação conjunta para forjar medidas concretas do Estado em resposta às causas e efeitos da seca na vida das populações rurais mais empobrecidas (I Seminário Pernambucano, Seca: Implicações políticas e formas de enfrentamento, 1990, p. 22).

Observa-se aqui duas posições. De um lado, o movimento sindical, as assessorias populares e os pesquisadores, responsáveis por sistematizar experiências alternativas capazes de "desmascarar, com fundamentos, as ações do Estado (municipal, estadual e federal) que tem se caracterizado pela manipulação e exploração do povo em momentos de agravamento das suas condições de vida e de trabalho" (I Seminário Pernambucano, Seca: implicações políticas e formas de enfrentamento - Relatório, 1990, p. 03). E, de outro, as intervenções do Estado (federal, estadual e municipal), em certa medida, contribuindo para consolidar a "indústria da seca" e a dependência dos agricultores aos políticos locais.

No entanto, é a posição política do Estado que sustenta os conceitos e princípios da convivência com o semiárido; ora com base no enfrentamento e no contraponto, ora no diálogo com a sociedade civil, no esforço de elaboração de um programa de convivência; e, ainda, buscando implementar, através dos próprios entes federativos, um Plano de Convivência com o Semiárido. O caso estudado, a partir do município de Serra Talhada é revelador do conflito, entre o desinteresse relacionado à “coisa do Estado" e o interesse tácito em dominar o seu espaço.

\section{O ALCANCE POLÍTICO DA CONVIVÊNCIA COM O SEMIÁRIDO EM QUESTÃO}

No início dos anos 90, do século XX, Serra Talhada foi palco de uma disputa política assumida pelo Fórum Seca, com a presença de Luis Inácio Lula da Silva dominando o discurso, "não enquanto apenas o presidente do Partido dos Trabalhadores, não enquanto coor- 
denador do Governo Paralelo, mas enquanto cidadão brasileiro preocupado em acabar com a fome nesse país” (Dossiê Fórum Seca, 1991):

O Fórum Seca pode tocar nessas coisas e pode, a partir de agora, mostrar pra sociedade brasileira que existe um Fórum, que não é uma coisa do Estado, não é uma entidade governamental, não está a fim de viver do dinheiro do Estado, mas é uma entidade civil representada por vários segmentos da sociedade, que está disposta a levar a questão da seca mais a sério do que já foi levada até hoje no Brasil. Nós temos que deixar claro que a questão da seca no Nordeste não é uma questão conjuntural, é uma questão de mais de séculos, portanto, a gente não pode ficar ano após ano esperando cair chuvazinha, porque nem sempre a chuva é suficiente. (...) E o Fórum, como não é de partido político, não é de um sindicato, mas de diversos segmentos da sociedade, pode contribuir de forma decisiva para que a gente dê outra dimensão à discussão da seca no Nordeste brasileiro" (Dossiê Fórum Seca, 1991).

Doze anos depois do Fórum Seca, acontece a posse do Lula como presidente do Brasil. Neste momento, a iniciativa da ASA se tornava oficial com a implantação do "Programa de Formação e Mobilização Social para a Convivência com o Semiárido: Um Milhão de Cisternas Rurais" (P1MC), concretizando uma agenda entre o Governo e a ASA, em torno de programas que tivessem como princípio a convivência com o semiárido (Passador; Passador, 2010; Diniz; Piraux, 2011b).

Com o P1MC, estava em jogo um instrumento potencial de distinção que buscava distanciar-se das políticas assistencialistas e emergenciais de outrora, a partir de uma narrativa centrada no discurso da convivência, através de tecnologias sociais capazes de proporcionar o envolvimento das famílias beneficiadas com a construção das cisternas de placas, através dos sistemas de mutirão e mobilização social que perpassariam as ideias da sustentabilidade e do trabalho coletivo, com a pretensão de ir além da transferência de ativos e distribuição de renda (Malvezzi, 2007; Andrade; Queiroz, 2009; Passador; Passador, 2010).

Para isso, seria necessário fortalecer a crença no capital social, ampliar as redes de relações entre os indivíduos para viabilizar ações cooperativas. Através do fortalecimento da sociedade civil, da mobilização, do envolvimento e da capacitação das famílias, com uma proposta de educação popular e emancipatória, a ASA uniria os esforços para construir uma cultura de valorização e crença na organização social através de novas institucionalidades (Passador; Passador, 2010).

Na prática, a estratégia do P1MC era desafiadora, uma formação que dizia respeito tanto ao governo, como às organizações da sociedade civil, no compartilhamento das responsabilidades para a concretização dos objetivos pretendidos por ambos. Nessa perspectiva, a convivência com o semiárido assumiria formas reconhecidas de legitimação política no interior do Estado, perfilando as ações públicas.

Nas Diretrizes para a Convivência com o Semiárido, publicadas em 2013, o discurso da convivência estava associado a uma retomada do ativismo e do protagonismo da sociedade civil. Os governos, enquanto atores da ação coletiva, assumem a força motriz em torno de uma plataforma de ações permanentes e articuladas, a partir de um Plano Nacional e de Planos Estaduais e Municipais de Convivência com o Semiárido. O Plano Municipal de Convivência com o Semiárido no Município de Serra Talhada surge também neste processo. Após um período de seca que marcava a região e um momento eleitoral favorável à permanência do Partido dos Trabalhadores no poder, com as eleições municipais (2012) e federais (2014), a promoção de uma conferência - "Conferência para a Construção do Plano Municipal de Convivência 
com o Semiárido" de Serra Talhada - conquistava a cena política, trazendo como base propulsora a Secretaria de Agricultura Familiar do Município.

Nesse sentido, as ações, antes conduzidas pela própria Secretaria, passaram a ser institucionalizadas e apresentadas como ações estratégicas voltadas à convivência com o semiárido. Com o formato participativo da citada Conferência, tal como sugerido no convite enviado às associações, sindicatos etc, e a parceria com o então Deputado Estadual Manoel Santos (PT-Pernambuco), através da mediação do seu assessor, o peso simbólico do Partido dos Trabalhadores estava garantido.

Com este formato, interesses diversos e conflitantes se tornaram convergentes, uma vez que o Plano Municipal levou para a arena tanto demandas da sociedade civil, quanto do poder público. Assim, a sistematização do plano resultou em uma confluência de interesses. No entanto, a convivência com o semiárido passa a ser tratada como uma "questão de interesse de governo”, particularmente da Secretaria Municipal, sendo o município de Serra Talhada o responsável pela implantação de determinadas culturas, mesmo no contexto de uma grande seca, com a caprino-ovinocultura como atividade pecuária. Com esse tipo de arranjo, a incorporação do discurso da "convivência" pelo Estado questiona a própria noção de sociedade civil, uma vez que a proximidade de interesses e objetivos vai deslocando a posição crítica da sociedade civil e o seu engajamento político.

Com intuito de evidenciar esta reflexão, vamos utilizar fragmentos da discussão proferida na Plenária do Plano de Convivência com o Semiárido de Serra Talhada, ocorrida um mês depois da Conferência, na Universidade Federal de Pernambuco (UAST), durante o "IV Seminário NEPPAS: caminhos, olhares e práticas da agroecologia nos sertões de Pernambuco”, promovido pelo Núcleo de Estudos, Pesquisas e Práticas Agroecológicas do Semiárido, com a intenção de dar continuidade ao debate da Conferência.

Porque é irônico o que aconteceu, em 2012 quando nós pensamos no planejamento da secretaria de agricultura daqui de Serra Talhada, nós convidamos alguns parceiros, uns dez parceiros, entre eles o conselho municipal, o Cecor, o IPA a ADAGRO, o PAA (...) pra construção do Plano de trabalho da Secretaria, dentro desse plano de trabalho a gente pensou ter um plano, só pensou não, dentro desse plano vamos construir também um plano de convivência com o semiárido até porque também tá na moda, né, tá na moda também falar em semiárido, antes se falava em combate à seca, só o povo da ASA que falava em semiárido (...).Esse plano foi tomando maior dimensão do que a gente esperava né, as cobranças também são grandes em relação ao que se fazer no município, por onde fazer, quando começar, o governo sozinho não tem condições de fazer, não é, isso é fato, a Prefeitura não tem condições sozinha de fazer tudo, as ONG's sozinhas ficam soltas, muitas vezes um tá aqui fazendo a mesma coisa que a outra (...) Então isso é possível porque a gente construiu um plano ouvindo todo mundo e nesse plano foi colocado lá coisas que a gente sabe que não é competência do plano municipal de executar, tem outras coisas né, a gente vai dividir tarefas com outros parceiros, com outras unidades e com outras instituições e a gente tá aberto pra colher opiniões, sugestões, propostas e receber pessoas que possam ajudar a gente a melhorar e a construir esse plano para o município de Serra Talhada, que a princípio, pelo menos no meu pensamento, era uma coisa e, na Conferência Municipal, transforma-se em outra. Eu pensava que era o plano municipal da Secretaria de Agricultura do município de Serra Talhada, e a gente tá vendo agora que não é mais isso, é o plano municipal de todas as instituições, de toda a população de Serra Talhada, do município de Serra Talhada (Secretaria de Agricultura Familiar de Serra Talhada, Plenária 
proferida no IV Seminário NEPPAS: caminhos, olhares e práticas da agroecologia nos sertões de Pernambuco, em abril de 2014).

O conteúdo desta entrevista ilustra a trajetória de apropriação do discurso da convivência com o semiárido pelo Estado, disposto a transferir suas responsabilidades e justificar seus interesses, enquanto Secretaria da Agricultura Familiar de Serra Talhada, para a sociedade civil; esta, sim, encarregada por ser "protagonista" de um Plano Municipal de Convivência com o Semiárido. No entanto, todo esse esforço de criação do Plano, levado a cabo pela Secretaria da Agricultura, embora tenha garantido a mobilização do discurso da sociedade civil, na prática foi mais um caso já conhecido, em que leis são criadas, decisões são referendadas, mas não são implementadas, tendo como resultado o engavetamento. Esse foi o desfecho do Plano $\mathrm{Mu}-$ nicipal de Convivência com o Semiárido, que passou a existir somente como estratégia discursiva, e de marketing político (Sieber; Gomes, 2016).

\section{O CAPITAL POLÍTICO DA CONVIVÊNCIA COM O SEMIÁRIDO NO MUNICÍPIO DE SERRA TALHADA: ENTRE O FAZER E O FAZER CRER DO PARADIGMA}

É possível afirmar que em Serra Talhada são bastante conhecidas as histórias de atores políticos, cujo percurso teve início no movimento social e terminou na disputa em pleitos eleitorais. O caso do Manoel Santos é o mais emblemático para a nossa discussão. Com origem na Ação Católica Rural (ACR), entre os anos de 1973 e 1978 do século XX, a trajetória de Manoel Santos é reveladora da influência da Igreja na formação de lideranças políticas, cuja trajetória política é marcada pelo trânsito institucional, movimento-estado, que, neste caso, é representado por um começo no movimento sindical, chegando à direção do Partido dos Trabalhadores (PT) no estado de Pernambuco, enquanto deputado estadual.

Conhecemos a trajetória do Secretário da Agricultura Familiar de Serra Talhada através da entrevista. Do movimento sindical, o Secretário conseguia mobilizar o discurso da convivência com o semiárido no âmbito do Estado, com o apoio do próprio Manoel Santos e da UFRPE.

Como eu venho de movimento, há anos eu já venho discutindo a questão do meio ambiente. O movimento sindical, ele sempre tem esse cuidado, essa preocupação de cuidar da natureza e da preservação, então devido eu estar vindo de movimento eu não tive muita dificuldade. E quando eu cheguei na Secretaria não tinha esse projeto aqui e nós resolvemos implantar e criar esse plano de convivência com o semiárido. Então isso facilitou. Nós tivemos o apoio também do gabinete do Deputado Manoel Santos, que enviou um engenheiro agrônomo, Flavio Duarte, que deu uma contribuição enorme à construção desse plano. E isso facilitou o nosso trabalho. Mas a ideia partiu da gente mesmo. Porque nós já viemos trabalhando há décadas esse trabalho de preservação e de convivência com o semiárido. (...) Apresentamos a nossa ideia, o que eu pretendia fazer pra que sustentasse a população rural e todos concordaram e a gente começou a agir, começamos a fazer contato. Sim, teve a Universidade Federal de Pernambuco, também, a Universidade Federal também participou da construção desse plano, na pessoa do João Amorim. Então isso nos ajudou e fortaleceu a conjuntura da criação desse plano. Então o contato foi esse. Foi com as organizações, instituições (Secretário da Secretaria da Agricultura Familiar de Serra Talhada, entrevista realizada em agosto de 2014). 
Diante da eleição municipal ocorrida em outubro de 2016, o referido Secretário abre mão da Secretaria para se candidatar a vereador do município, perdendo a eleição. No entanto seu cargo estaria garantido com a reeleição do prefeito, fazendo com que o Secretario fosse reconduzido ao cargo.

Este constante trânsito institucional feito por militantes sociais-partidários, entre diferentes espaços de atuação, faz do paradigma da convivência uma oportunidade de legitimação no campo político, onde o Estado se torna espaço de confluência de interesses e disputa, permeável às propostas da sociedade civil (SILVA; OLIVEIRA, 2011; DAGNINO; TEIXEIRA, 2014). O dirigente da FETAPE nos trouxe um pouco deste aspecto, fazendo menção à figura de Manoel Santos, já que não pudemos entrevistá-lo pela ocorrência do seu falecimento.

É, na verdade, você quando entra na luta começa a pensar em transformação e a verdade a gente tem que colocar que a coisa vai em passos. A própria visão da Igreja e sindical, a princípio era que político e sindicato não se juntavam, era o que a gente chamava água e óleo. Só que o tempo vai passando e inclusive eu escutava muitas vezes o Manoel dizendo: entrei no movimento sindical e pensei que dentro de cinco, seis anos eu conseguia transformar o mundo. Foi se percebendo que a gente queria ocupar outros espaços de transformação. Isso é questão de consciência mesmo. A gente tem que ter os espaços de transformação, porque se a gente não ocupar os espaços, os outros ocupam e nós vamos ficar a vida toda só reclamando. E foi daí que começou as pessoas acharem que tinha que fundar um partido, tinha que ter um partido que representasse esses trabalhadores, então todas as pessoas que estamos colocando aí se filiaram ao partido, o PT. Na verdade, foram fundadores do PT Manoel, Raimundo foi, todos eles foram fundadores. Inclusive Raimundo Aquino foi o primeiro candidato do PT aqui em Serra Talhada nos anos 80. Foi até candidato a prefeito, onde fazia campanha em cima de um tamborete, não era pensando em se eleger, era pensando em mostrar a sociedade que tinha alternativas. E assim foi se discutindo a necessidade de ter um candidato a vereador, de ter candidatos que lançassem candidatos a prefeito pra mostrar a oposição, que começou a batalhar, ter candidato à presidência da república, porque nós távamos tendo claro que a questão da convivência com o semiárido e a transformação da sociedade passa pela aquisição de políticas públicas, porque no Brasil não temos aquele povo para fazer a revolução, então se você não ia fazer a transformação através da revolução, teria que ser através da política (Dirigente da FETAPE de Serra Talhada, entrevista realizada em maio de 2015, grifos nossos).

A narrativa desse informante possibilita apreender o objetivo mais geral, digamos a utopia, que alimenta o movimento em torno da convivência: a transformação da sociedade. $\mathrm{O}$ crescente processo de sindicalização rural, orientado pela Igreja Católica, e com uma vertente transformadora, era uma estratégia para promover a organização dos agricultores pobres do Nordeste (Favero, 2006).

Assim, ter adentrado na comunidade cristã é uma característica comum na trajetória de vida de lideranças, guiadas por uma crença revolucionária, de transformação da sociedade. Foi por essa via que a convivência com o semiárido adquire um alcance político efetivo, via políticas públicas, costurando o diálogo em diferentes esferas, entre sociedade civil e Estado, durante os governos liderados pelo Partido dos Trabalhadores.

Destacamos o papel fundamental da Diocese de Afogados da Ingazeira (PE), impulsionando a formação de lideranças importantes no município de Serra Talhada e para o Partido dos Trabalhadores. Algumas dessas lideranças passaram a atuar na gestão pública, outras em ONGs, as quais foram essenciais para o amadurecimento do paradigma da convivência com o semiári- 
do, a exemplo do Centro de Educação Comunitária Rural (CECOR-1994), que é uma referência no município. Nasce de um Projeto da Diocese de Afogados da Ingazeira, na década de 80 - Projeto de Educação Comunitária Rural (PECOR) -, que, além de apoiar os movimentos sociais, tinha a Diocese como intermediária, uma mediadora importante nas negociações com as agências de Cooperação Internacional.

Tanto o CECOR, quanto o Sindicato dos Trabalhadores Rurais do município de Serra Talhada e outros políticos locais do Partido dos Trabalhadores tiveram a mesma formação para a militância, além de terem valorizado o "rural" enquanto espaço de investimento e formação de um eleitorado petista, que tem na figura de Manoel Santos um líder local autêntico, nascido e conhecedor das necessidades do lugar.

Outra arena importante para acessar de maneira quase fotográfica a relação entre a sociedade civil e o Estado é o Conselho Municipal de Desenvolvimento Rural Sustentável. As disputas no interior do CMDRS evidenciam uma relação bastante estreita entre o Poder Público Municipal e o Conselho, que parece se transformar em um espaço de "negociações políticas". O sentido do "político", aqui, está relacionado a determinado "balcão de negociatas" para favorecer sucessões de cargos na prefeitura: o atual Prefeito foi presidente do Conselho Municipal de Desenvolvimento Rural Sustentável de Serra Talhada e são inúmeros os candidatos a vereadores que também o foram, ou assumiram outro tipo de função. O prefeito, obviamente, não assumiria isso, associando certa “pelegagem” às ações pregressas do Conselho:

Quando eu entrei o conselho já existia, nós fortalecemos o conselho. O conselho era um conselho muito de... não era pelego não, mas era do presidente andar com o livro de baixo do suvaco. Como é que chama? Era o meu conselho. Não era um conselho dos agricultores, ou seja, tinha dono. (...) O conselho, ele é tão forte que não tem nenhuma interferência da prefeitura, tanto é que eu fui vice-prefeito e as pessoas achavam que o conselho dependia da prefeitura e ele só andava porque eu era vice-prefeito. Hoje eu sou prefeito e o conselho continua aí funcionando independente de prefeitura. E quem quer que entre na prefeitura o conselho vai continuar funcionando, porque ele tem uma relação intrínseca muito forte com o sindicato, não é, e com as organizações sociais, e é uma casa dos agricultores. $80 \%$ da estrutura dele são as associações rurais. Então não há interferência direta da política, pelo contrário, a política na sua transversalidade contribui com o conselho, más não interfere diretamente (Prefeito do Município de Serra Talhada, entrevista realizada em janeiro de 2015).

De fato, a trajetória dos movimentos sociais em Serra Talhada e região sofreria um deslocamento com o passar do tempo. De acordo com o prefeito, de uma versão "comunista" atribuída aos movimentos sociais nas décadas de 70, 80, e, principalmente nos anos 90, com a participação dos agricultores nos sindicatos, haveria uma ressignificação das ações dos movimentos sociais, com base na organização de associações e no acesso às políticas públicas:

Pesquisadora: E isso você enquanto presidente do Conselho?

Prefeito: Aí eu comecei a andar nas comunidades, reunir o povo organizar as associações, discutir com a comunidade a importância da criação da associação, o porquê, então o que possibilitou o que fortaleceu o programa garantia safra. Quando nós começamos a discutir o programa garantia safra, o primeiro programa tinha 640 agricultores, hoje tem 5000. Então a grande ferramenta que fortaleceu o movimento de criação de associação foi o programa garantia safra, e outros programas que surgiram ao longo também (Prefeito do Município de Serra Talhada, entrevista realizada em janeiro de 2015). 
O discurso da convivência com o semiárido se desenvolve em um ambiente marcado pela tensão entre o alcance político da sociedade civil, representado pelo avanço dos movimentos sociais, pelo crescimento dos arranjos associativos e pela consolidação de espaços públicos e democráticos, e a sua incorporação pelo Estado, performatizado por um Plano Municipal de Convivência com o Semiárido, pautado na crença de que a política e os processos de tomada de decisão estariam sendo reconfigurados. Até então, na prática, a convivência, em sua essência, estaria sendo trabalhada pelas ONGs e alguns órgãos públicos, através da implantação das tecnologias sociais e dos projetos de atuação de cada entidade. No entanto, um diálogo direto com o Governo, no âmbito municipal, teria na construção do Plano uma conquista política.

Pesquisadora: E por que você acha que Serra Talhada entrou como pioneira nesse plano municipal?

Prefeito: É pioneira porque nós fundamos, nós iniciamos a discussão, nós fizemos várias conferências e formatamos o primeiro plano de convivência. A partir daí passamos a adotar como prática algumas metodologias de convivência, e aí passou a fazer parte de política pública dentro do governo esse plano de convivência.(...) Tava dentro do eixo de desenvolvimento que nós queríamos adotar dentro do governo não é, se por ventura fôssemos eleitos. Como chegamos, a gente colocou como prioridade.

Pesquisadora: E quais são as suas expectativas em relação a isso?

Prefeito: Bom, não é uma construção muito fácil porque toda política que você vai construir de mudança de cultura, não é muito simples mudar conceitos, mudar é, forma de agir das pessoas não é muito fácil, más nós temos procurado capacitar nossos técnicos pra levar o conhecimento e temos conseguido avançar. Só que isso leva um certo tempo (Prefeito do Município de Serra Talhada, entrevista realizada em janeiro de 2015).

A política construída a partir da temática da convivência com o semiárido, incorporada pela prefeitura, traz um caráter de mudança cultural. Mudar conceitos e modos de atuação é o objetivo da gestão municipal, a partir da construção de uma matriz cognitiva e normativa, produtora de uma identidade específica, partilhada pelos atores em favor de um paradigma ou referencial (Muller; Surel, 2004).

Entretanto, este processo é permeado por disputas, fazendo com que cada ator faça valer seus próprios interesses. Por isso a produção de uma matriz cognitiva significa mais que um simples processo discursivo, é uma dinâmica intimamente ligada às interações e às relações de força que se cristalizam pouco a pouco, para chegar a fazer parte da agenda governamental ou não governamental.

O conceito de campo político de Pierre Bourdieu (2011a) tem amparado a construção de uma chave interpretativa que nos leva a refletir sobre o Plano Municipal de Convivência como um jogo político, no qual os princípios de visão e divisão do mundo social são guiados por ideias especificas, as chamadas ideias-força, que funcionam como força de mobilização, de universalização; força que impulsiona a ação das pessoas que compartilham determinada visão (Bourdieu, 2011a, p. 203). A convivência com o semiárido representava uma ideiaforça poderosa na esfera do governo municipal, capaz de mobilizar um capital político e tornar-se hegemônico a partir de certa aprovação religiosa e científica. Os atores, dotados de poderes desiguais, possuíam um objetivo comum, permanecer ocupando o Estado, que, em certa medida, põe fim à luta política, através da pactuação de interesses e do estabelecimento de consensos. Na medida em que o campo político conquistado pelo Partido dos Trabalhadores avançou, houve ganhos para o movimento social e sindical, tendo no Estado um meio de legit- 
imação de certas reivindicações, no sentido de fazer ver e de fazer crer através de ideias-força (Bourdieu, 2011a).

Com a aprovação do Plano Municipal de Convivência, as ações dos atores envolvidos passariam a ser reconhecidas como ações informadas pelo paradigma da convivência com o semiárido. Mas, na prática, não havia maiores alterações. Precisamos distinguir aqui dois movimentos: o primeiro compreende as atividades desenvolvidas pelas ONGs, relacionadas à implementação das tecnologias sociais levadas a público pela ASA e voltadas à convivência com o semiárido; e o segundo se refere à construção do Plano Municipal de Convivência com o Semiárido, enquanto incorporação do discurso pelo Estado. Vejamos este aspecto na seguinte fala:

Porque o Governo do Estado exigiu que cada município tivesse um Plano municipal. O município fez, desencadeou, procurou a Universidade que contribuiu, mas não leva adiante. Então eu vejo duas coisas. Eu vejo que enquanto na prática algumas ONGs, alguns movimentos tão fazendo na prática, sem esperar que exista uma Política, o Estado nas suas três instâncias não faz. Até tem planos, mobiliza pessoas, tem recursos, mas os Planos morrem, se acabam, né. Então assim, é um conflito, aliás, nem tem conflito, é uma contradição, não sei o que eu chamo, mas até seria bom que tivesse um conflito, uma pressão, seria excelente se tivesse uma pressão, uma disputa aí, um debate, não têm! A sociedade civil foi lá e participou, mas depois se calou. Tá fazendo na prática porque vem as ações do Centro Sabiá, vem as ações do CECOR, vem algumas ações pontuais da Universidade, vem alguns... cursos, vem algo do Projeto Dom Helder Câmara, vem uma coisa, vem outra coisa, mas não tem aquela coisa mesmo: estamos numa dinâmica de convivência com o semiárido, prefeitura municipal de Serra Talhada, mais o ITEP, mais o SEBRAE, mais a Universidade, mais as faculdades particulares, não existe isso... na prática, digo. O P1MC colabora muito porque tem os recursos, pra mobilizar, pra capacitar, o Programa Uma Terra e Duas águas, vem recurso do Pernambuco mais Produtivo, vem recursos de outros, da Cooperação, da Fundação Banco do Brasil, vão tocando, mas não é uma coisa assim, uma confluência entre movimentos sociais, ONGs e prefeituras, dando as mãos e levando, independente de quem votou em quem, levando adiante dentro de planos municipais (Gerente do Programa P1MC, entre os anos 2003-2009, professor da Universidade Federal Rural de Pernambuco Campus de Serra Talhada, entrevista realizada em novembro de 2014).

Constatam-se diferenças práticas entre as ações conduzidas pelo Estado e as executadas pela sociedade civil. Apesar das conquistas da ASA, no diálogo com o Estado experimentado na execução do P1MC, no âmbito local este diálogo institucional é bastante incipiente.

Eu acho que a ASA enquanto rede tá conseguindo aos poucos demonstrar, afirmar, ratificar essa questão do paradigma da convivência com o semiárido por meio de suas ações, isso, é claro, a visibilidade que isso tem, mas por outro lado assim, eu acho que a sociedade civil como um todo, falando de população, falando das pessoas que tão lá no meio rural, no meio urbano, das cidades pequenas (...) O alcance é muito pequeno, por exemplo, em nível local... não existem planos municipais de convivência com o semiárido, nem existem planos estaduais ainda de convivência com o semiárido. Pernambuco aponta, diz que tem um plano, mas ninguém vê esse plano (...) Eu acho que não alcançou esse nível ainda, da institucionalização, de ter planos municipais, estaduais, com suas convergências que pudessem de fato (...) Embora em vários Estados, principalmente do governo Lula pra cá, a gente vê pessoas que fazem parte da ASA, dos movimentos, que estão nos Governos estaduais, nos governos municipais, no governo Federal, mas ainda não tem tido a preocupação de levar essa pers- 
pectiva da convivência pra Planos, pra programas de governo, pra programas de Estado... (Gerente do Programa P1MC, entre os anos 2003-2009, professor da Universidade Federal Rural de Pernambuco, entrevista realizada em novembro de 2014).

O fato é que, na esfera do poder público municipal, a convivência com o semiárido se materializa sob a forma de um plano fantasma que tem servido para justificar as ações da própria Secretaria da Agricultura, claramente reduzidas a duas dimensões: disputa pelo acesso a cargos políticos e acesso aos programas e políticas públicas.

Em geral, para aqueles que atuavam na esfera do Estado, o capital social vai se tornar, na prática, capital político, orientando as ações dos atores em disputa. Neste campo, o discurso se desenvolve de modo ambíguo, ou seja, os princípios reproduzem práticas e metodologias fortemente criticadas pelo paradigma da convivência: as velhas ações assistencialistas de combate à seca (SIEBER; GOMES, 2016).

\section{PARA EFETIVAR O DISCURSO DA CONVIVÊNCIA: DISPUTAS, PODER E DOMINA- ÇÃO}

Entre o esforço de construção e valorização de saberes e conhecimentos desenvolvidos ao longo do tempo pelas populações rurais, no contexto de uma natureza que precisa ser conservada (Cunha; Paulino, 2014), e a adesão a um modelo de convivência, pautado em novas formas de pensar e agir no semiárido, capaz de melhorar as condições de vida e promover a cidadania (Silva, 2006), constata-se uma discordância do poder público local que atua contrariando as iniciativas da ASA em relação à produção de conhecimento, à democratização do acesso à terra e à água.

É muita disputa em todos os sentidos, cultural, ambiental, social. É um ambiente bem carregado de tudo, de muitas manifestações, de muitas relações ainda desiguais. Isso não dá pra negar, o tempo todo a gente se depara com isso, o poder público local atua de forma muito perversa, segregando centenas de associações comunitárias rurais que ainda não têm, não estão no estado de reivindicar, de pautar, algumas aqui já se sobressaíram. Eu acredito que a ASA com as ações do programa Um milhão de Cisternas contribuíram muito para ampliar esses debates. (...) Então, é tanto que a perspectiva de convivência com o semiárido hoje ela já é bastante alastrada, já bastante compreendida neste sentido que as pessoas... não tinham essa noção. Era o pipa pra colocar água onde tivesse fila, a briga pra fazer a água. Na medida que as pessoas começam a debater, a conversar, a compreender que ali existe um poder público que gere recursos,... Que pode existir sim uma confluência, que pode participar, que pode reivindicar, que pode organizar, que pode debater sim como cidadão, como cidadã. E isso tem gerado algumas mudanças bem interessantes. Pra mim então uma das mudanças é essa compreensão da convivência com o semiárido como nosso ecossistema, é o que temos, é o que temos esse regime cada dia mais irregular de chuvas. É essa complexidade toda (Gerente do Programa P1MC, entre os anos 2003-2009, professor da Universidade Federal Rural de Pernambuco, entrevista realizada em novembro de 2014, grifos nossos).

A narrativa do professor explicita os jogos e interesses que permeiam a convivência com o semiárido no município de Serra Talhada, mas certamente essa é uma situação exemplar do que ocorre em outros municípios do semiárido nordestino. 
A dinâmica social produzida pelo chamado paradigma da convivência revela uma sociedade civil capaz de reivindicar, de pautar e de compreender que existe um Estado com poder para gerir recursos, implementar processos, produzir e legitimar narrativas. Estamos falando de uma sociedade civil mais ativa, que dialoga com o Estado e que tem na ASA um mediador importante. Esse mediador é o Professor, ao narrar detalhes da sua trajetória de vida, enquanto gerente da ASA, entre os anos de 2003 e 2009:

Pra cada instituição tem um conjunto de estratégias, né, a gente também foi aprendendo a criar junto essas estratégias pra discutir, por exemplo, com a Federação Brasileira de Bancos. Não seria uma contradição buscar dinheiro da Federação Brasileira de Bancos para financiar cisternas? Por outro não, não seria uma contradição. Dinheiro do lucro que eles têm e pode muito bem ser investido no semiárido para mobilizar pessoas, para capacitar pessoas, para construir reservatórios de água de chuva nessa perspectiva da convivência com o semiárido (...). Mas a gente foi entendendo e aprendendo a gerir recursos financeiros, a prestar contas. Também, por outro lado, foi aprendendo a enfrentar prefeitos e prefeitas que não queriam as cisternas, ou que declaravam, escancaravam que esse dinheiro deveria ir pras prefeituras e não pras ONGs. Então tivemos conflitos de todas as naturezas. (...)E a nossa estratégia era fortalecer essa base. As famílias precisavam de água? Precisavam. Então elas estão organizadas em suas associações, suas associações em sindicatos, seus sindicatos em Federações. Então vamos dar as mãos, então vamos enfrentar, Prefeito e Prefeita não vai fazer isso. A CODEVASF mesmo, gestores de CODEVASF, políticos, não entendia porque esse dinheiro não ia pras prefeituras. E a gente dizia não, vai pra mão da sociedade civil, porque é ela quem... é aqui que nós estamos aprendendo nossos processos, fortalecendo nossos processos e principalmente aprendendo a gerir recursos públicos, valorizando cada centavo. (...) E então foi muita luta, ainda é uma luta (...) (Gerente do Programa P1MC, entre os anos 2003-2009, professor da Universidade Federal Rural de Pernambuco, entrevista realizada em novembro de 2014).

O relato acima descrito é um exemplar do que Diniz (2007) tratou como "experimentalismo institucional", um tipo de relação que se expressa no interesse da ASA em manter-se próxima ao Estado. Esta aproximação com o Estado implicou, ao mesmo tempo, uma redefinição da sociedade civil, ou seja, no processo que envolveu a efetividade da Convivência com o Semiárido, a sociedade civil não se coloca mais contra o Estado, situação vivenciada no período da ditadura. A possibilidade de uma ação conjunta, orientada pela participação da sociedade civil, se tornava central como característica distintiva de um projeto democrático (Dagnino, 2004a, 2004b).

Contudo, esse arranjo não extinguiu as velhas práticas de combate à seca; essas se reproduzem no âmago da confluência perversa da convivência com o semiárido, na relação entre a sociedade civil e o Estado. A conjuntura política, marcada pela gestão de um partido democrático, possibilitou uma dinâmica de trânsitos institucionais que levaram a cabo algumas demandas dos movimentos sociais e à criação de espaços de participação da sociedade civil, com destaque para o programa Fome Zero e o Bolsa Família. As tensões e contradições provenientes desses programas "bem sucedidos" podem expressar não só a diversidade de posições em face da participação dentro do governo, mas também a emergência de um arranjo que, de acordo com Dagnino e Teixeira (2014), pode significar o renascimento da concepção do Estado como agente fundamental de transformação social, aparentemente pautado na ruptura com o projeto neoliberal e inclusão de uma democracia participativa no governo da Presidente Dilma Roussef. 
A minha leitura é que, assim, a gente conseguiu avançar, porque a chamada sociedade civil, ela começou a perceber a necessidade de estreitar esse diálogo era necessário pra gente interferir nas políticas públicas. Porque a gente constrói as propostas na base pra que elas se tornem políticas também (...) E a gente começou a perceber que precisava estreitar esse diálogo, o que não significa compartilhar com o pensamento do Estado, não significa que a gente não tem uma visão crítica do Estado e dos governos. Mas eu acho que a gente conseguiu romper com uma barreira das organizações que vieram da ditadura mesmo, a gente não tinha naquela época como dialogar com o governo né, porque era uma estrutura extremamente repressora, não dava pra dialogar, eu acho que algumas coisas começaram, né, a mudar, inclusive algumas pessoas que tavam nos movimentos sociais, né, são cooptadas pelos governos, eu acho que isso também deu mais abertura pra que esse diálogo fosse travado. (...) Claro que essas pessoas, algumas foram pros governos não numa, numa conjuntura que favorecesse a sua ação, né, a partir do modo como pensavam nos movimentos sociais, porque dentro do governo a gente sabe que existe um campo de disputa como na academia, um campo de disputa que é duro, é bem pesado. (...) Então, assim, não é uma coisa muito fácil não (Coordenadora local do Centro Sabiá, entrevista realizada em setembro de 2015).

As ONGs também aderem a uma lógica marcada pela confluência, entre um lugar de oposição e a necessidade permanente de dialogar com o Estado, dando origem a uma relação necessária para operacionalizar programas sociais e políticas públicas. Neste contexto, a noção de participação é fundamental para que o diálogo com o Estado aconteça e seja capaz de substituir a própria noção de distinção entre a sociedade civil e o Estado. Um pouco desse processo é narrado na entrevista com a coordenadora local do Centro Sabiá de Triunfo:

Eu acho que a Articulação do Semiárido foi o primeiro Fórum da sociedade civil que começou a fazer uma discussão mais estreita com os governos, que foi no surgimento justamente do Programa Um Milhão de Cisternas, concretizando uma proposta da sociedade civil, numa política pública. Então, pra mim, é uma política pública executada pela sociedade civil. Eu acho que esse programa é o momento mais simbólico desse diálogo, né, com os governos. E esse diálogo, ele tem se dado muito. Eu acho que o jogo é tentar interferir na construção dessas políticas que não tem sido uma tarefa simples. Mas é o que a gente tenta, através dos espaços de controle social, através dos conselhos, né, os conselhos municipais, os conselhos estaduais que foi assim, foram espaços que acabaram surgindo a partir de uma pressão da população, dos movimentos que permite uma interferência da sociedade nas políticas em alguns casos (...) Então eu acho que, acho que essa relação, ela ainda é bastante conflituosa, ela não é uma relação tranquila em absoluto, mas foi necessário que ela se desse, pra que a gente conseguisse avançar nesses processos. E até mesmo pra que a gente fosse mais coerente com o nosso discurso de que a gente precisa, a população precisa ser participativa, né, aí não bastava só jogar pedra na vitrine. (...)E as vezes a gente se vê num... assim, a gente se vê em determinadas situações tipo, em ter que dialogar com grupos do governo que você discorda dos posicionamentos, discorda das propostas políticas desses grupos. Mas você tem que fazer esse diálogo, e aí de ter muito cuidado de não perder autonomia, né, de ter sempre uma visão crítica desses processos. Mas ao mesmo tempo eu faço uma leitura de que a gente não pode perder a oportunidade, por exemplo, de ter recursos pra colocar em prática a proposta da construção da agroecologia no semiárido, por exemplo, de colocar em prática as nossas propostas de convivência com o semiárido, né, de estar construindo as tecnologias sociais junto dos 
agricultores, nas comunidades (Coordenadora local do Centro Sabiá, entrevista realizada em setembro de 2015).

A narrativa acima evidencia a dinâmica na qual os diálogos acontecem; em geral, de forma conflituosa e ambígua. De um lado, a necessidade de manter uma postura crítica em relação às ações do Estado; de outro, o risco da perda de autonomia, frente à necessidade de acesso a recursos.

Para o Coordenador do CECOR, a relação que se estabelece para acessar financiamentos contribui para reproduzir determinadas posições e atividades. $\mathrm{Na}$ época em que o financiamento das ONGs se baseava fundamentalmente nos acordos com a Cooperação Internacional - que no caso do CECOR era mediado pela Diocese de Afogados da Ingazeira -, a ONG apresentava a demanda à instituição para obter apoio. Atualmente, este processo se inverteu. A ONG passou a executar ações para o governo, o que resultou em uma relação de dependência dos recursos concedidos pelo Estado.

Até o momento que a gente tinha recurso da cooperação internacional a lógica era um pouco inversa de hoje. O CECOR apresentava a demanda pros agricultores, pra instituição e a instituição apoiava a nossa proposta. Agora é o inverso. O governo apresenta a demanda e a gente, se quiser participar, você entra naquilo que já tá pronto e preparado, então isso é meio perverso e nós estamos ainda tentando resolver (...) agora nós estamos executando uma proposta que não é nossa de uma forma... De uma forma também é nossa... Mas não é exatamente a nossa proposta. Nós temos, por exemplo, a chamada de Ater Agroecologia do MDA, nós estamos em execução nesse momento, que do ponto de vista do conteúdo, grande parte surgiu da sociedade civil organizada, das ONGs em particular, mas do ponto de vista da operacionalização ainda tem muito da burocracia do governo, de que é a lógica do serviço público. Então isso é perverso, mas a gente aos poucos tenta ir resolvendo, mas constitui um desafio (Coordenador do CECOR, entrevista realizada em setembro de 2014).

Essa dinâmica não exclui as demandas da sociedade civil. Um ou outro tema é incorporado à agenda governamental, representando um avanço para as organizações; mas isso parece depender do trânsito institucional, discutido por Silva e Oliveira (2011), quer dizer, um trânsito que implica a habilidade de ocupar posições nos espaços de governo, de flexibilizar editais lançados para assegurar a prestação de serviços. Tudo isso reforça as semelhanças entre o Estado e a sociedade civil.

Os fluxos de interesses, ou trânsitos institucionais, possibilitam que as pautas das ONGs interfiram na agenda do próprio Estado. No entanto, essa interferência produz uma espécie de amálgama, que dificulta a validação das especificidades inerentes às diferentes instituições, regiões, municípios, etc. O fato é que, em todo o período dos governos do PT, as ONGs foram alvo de interesses do Estado, seja pela capacidade de assegurar eficiência técnica, seja pela competência de formular e executar projetos. Mas há outro viés de análise nesse processo que não podemos deixar de refletir e que implica o fato de as ONGs (ASA, Centro Sabiá, entre outras) terem sido parceiras na execução dos projetos e ações de políticas públicas, e que essa parceria tenha balançado a "autonomia" distintiva do terceiro setor (DAGNINO, 2002).

E também é o seguinte, as organizações não governamentais elas têm o conhecimento e a propriedade, né, do ponto de vista da aplicação das diversas tecnologias propostas pela convivência com o semiárido. Quem construiu essas propostas na base foram essas organizações. Então os organismos de governo, 
eles não têm nohall pra isso. O governo reconhece isso. Então, não é sem interesse que o governo, por exemplo, contrata as organizações não governamentais também nas chamadas de Ater, não é à toa que o projeto Dom Helder Câmara, né, fez uma parceria com as organizações não governamentais. Porque o Projeto Dom Helder Câmara, que é ligado também ao MDA, que foi pensado justamente pra construir propostas de Ater que respondam às questões, principalmente dos assentamentos rurais, né. De pensar uma Ater diferenciada que não fosse aquela Ater pública, que vinha já com o pacote pronto pros agricultores (Coordenadora local do Centro Sabiá, entrevista realizada em setembro de 2015).

Ao final, considera-se que o paradigma da convivência pressuponha uma sociedade civil protagonista, cuja a origem e os princípios advenham de um espaço não estatal. Esta dinâmica desloca o discurso de combate à seca, disputando a hegemonia do repertório da convivência com o semiárido, e revela um setor da sociedade civil que, ao mesmo tempo que se apresenta em oposição ao Estado, parece sobreviver das práticas e ações governamentais comprometidas com a efetivação do paradigma da convivência. Considerando a conjuntura política atual, de um governo conservador, considera-se que a habilidade das ONGs em negociar com o Estado pode ser aproveitada enquanto estratégia de resistência; reinventando as ações políticas e revisitando histórias, desconstruindo problemas e construindo saberes de forma comprometida e dialogada.

O Partido dos Trabalhadores manteve, durante os últimos 20 anos, uma postura efetiva na ampliação de canais e espaços institucionais de compartilhamento para a gestão das políticas públicas, com a sociedade civil. Essa dimensão, sem dúvidas, foi um marco importante na trajetória das ações voltadas ao desenvolvimento das áreas interioranas do Nordeste semiárido. A narrativa produzida pela convivência com o semiárido é exemplar do significado político do experimentalismo institucional, no qual o Estado, embora disputado, se dispôs a compartilhar com a sociedade civil a construção de um projeto político.

Assim, ao tempo que se tenta deixar mais nítida a diferença entre Estado e sociedade civil, amplia-se a possibilidade de diálogo entre ambos, o que se torna cada vez mais interessante para um projeto democrático e participativo. Para o futuro, espera-se que as ONGs continuem, enquanto braço da chamada sociedade civil, resistindo pela efetividade do discurso da convivência com o semiárido, apesar dos desafios que certamente enfrentarão. Os atores e mediadores envolvidos nesse processo continuam sendo sujeitos potenciais para o fortalecimento da relação entre a sociedade civil e o Estado, além de agentes efetivos de mudanças sociais que possam garantir direitos aos agricultores familiares e, por conseguinte, qualidade de vida à sociedade como um todo.

\section{CONSIDERAÇÕES FINAIS}

Os antecedentes da convivência com o semiárido manifestados pelo Fórum Seca (1989 e 1997) revelou um esforço de articulação capaz de mediar o potencial mobilizador da sociedade civil na direção do Estado, apesar de operar com um repertório discursivo e metodológico de oposição. Além de envolver eventos fundamentais destacados na literatura da convivência, a exemplo da ocupação da SUDENE e do Fórum Nordeste, o Fórum Seca justificou a centralidade de realizar a análise, aqui descrita, no município de Serra Talhada, no sertão pernambucano.

O alcance político da convivência com o semiárido tem sua legitimação com o P1MC. No entanto, para além das iniciativas da ASA e de outras ONGs parceiras, o repertório da con- 
vivência é incorporado pelo Estado na forma de planos municipais e estaduais. No Estado, a convivência assume mais uma forma discursiva, servindo, em alguns casos, para justificar as ações que já vinham sendo conduzidas. Este modus operandi, no caso da implementação das ações da convivência e na relação entre movimentos sociais-ONGs-Estado, se faz presente, concomitantemente, ou preponderantemente, nos interesses do próprio Estado, na incorporação de demandas e de projetos "políticos", orientados para a convivência com o semiárido.

O espaço social, de disputas e negociações políticas que se desenvolve no âmbito do Estado continua representando um espaço de cooptação (mesmo que desejado); uma vez que é nesse espaço onde a confluência perversa se legitima, modificando, às vezes, o formato dos projetos idealizados pela sociedade civil. Nesse sentido, os espaços públicos "não estatais" parecem funcionar, em alguns casos, como ferramenta da ação do governo municipal - o caso do Conselho Municipal parece atuar nesse sentido. Com a aprovação do Plano Municipal de Convivência com o Semiárido em Serra Talhada, temos um exemplo de como o prestígio do Estado se consolida, em um tipo de "estatolatria”, nos termos mencionados por Gramsci (2007). Ou seja, quando a vontade política do Estado é dominante, ainda que ações e decisões apareçam como produto do diálogo entre diferentes atores.

$\mathrm{O}$ ambiente institucional que predominou durante as gestões do PT se caracterizou em sucessivas tentativas de aproximação entre a sociedade civil e o Estado, com o objetivo de estimular e promover o compartilhamento de responsabilidades na execução de políticas públicas, reproduzindo arranjos institucionais jamais experimentados, mas que modificaram repertórios e metodologias dos movimentos sociais (Gohn, 2013).

A sociedade civil se coloca como contestadora dos interesses do Estado, que atua de maneira autoritária e excludente. No entanto, a experiência da convivência com o semiárido contradiz essa definição quase universalizada de sociedade civil, manifestada no esforço de diálogo em um ambiente institucional mais democrático e participativo. No caso da convivência com o semiárido, experimentada através de implementação do Plano Municipal, o exercício prático e político da confluência parece se materializar, através de decisões que resultam de constantes embates e negociações, nem sempre exitosas, segundo os objetivos e interesses da sociedade civil, ou do Estado.

A implementação do Plano Municipal de Convivência com o Semiárido, no município de Serra Talhada, vai revelar outras facetas desse "diálogo", sob uma face política na qual as ações, em alguma medida, parecem ser motivadas por um oportunismo eleitoreiro a despeito de uma trajetória significativa de luta política construída pelos movimentos sociais e sindicais. Da liderança de associações, ao sindicato e conselho municipal, da secretaria da agricultura para a câmara de vereadores, ou para a prefeitura do município, a convivência com o semiárido vai sendo transfigurada, envolvida por uma cultura de carreamento de capitais para uso e empoderamento pessoal. Contudo, todo esse processo teve um papel político importante, capaz de transformar uma demanda da sociedade civil em política pública, elevando a crença dos próprios atores na mudança social, mas secundarizando a visão do paradigma como transformação radical.

A experiência da Convivência com o Semiárido, analisada no Município de Serra Talhada (PE) evidencia as distinções entre o Estado e a sociedade civil, ao mesmo tempo que revela as fragilidades e interesses que, em diversos graus, fazem parte desse processo. Ante a conjuntura que se instaura pelo Presidente Michel Temer (PMDB), a vulnerabilidade da sociedade civil vem à tona, questionando sua resistência. Observa-se a extinção e o enfraquecimento de uma série de programas e ações públicas, e a desmobilização de vários espaços participativos (Fóruns, Conselhos, Associações, Colegiados, etc). A expectativa para o momento é que as ex- 
periências não caiam no esquecimento, que a crença na força política da sociedade civil organizada seja um impulso para nos livrar do medo e do comodismo.

\section{REFERÊNCIAS}

BOURDIEU, P. O campo político. Revista Brasileira de Ciência Política, n. 5, Brasília, janeiro-julho , 2011a, p. 193-216.

CUNHA, L.H.; PAULINO, J.S. Convivência com o semiárido: um novo paradigma para políticas públicas no Nordeste? In: Neves, D. P.; GOMES, R.A.; LEAL, P.F. (Orgs.) Quadros e programas institucionais em políticas públicas. Campina Grande: EDUEPB, p. 27-58, 2014.

DECLARAÇÃO DO SEMIÁRIDO. PROPOSTAS DA ARTICULAÇÃO NO SEMI-ÁRIDO BRASILEIRO PARA A CONVIVÊNCIA COM O SEMI-ÁRIDO E COMBATE À DESERTIFICAÇÃO. Recife, 26 de novembro de 1999.

DAGNINO, E. Confluência perversa, deslocamentos de sentido, crise discursiva. In: GRIMSON, Alejandro (Ed.). La cultura em las crisis latino-americanas, Buenos Aires: CLACSO, ConsejoLatinoamericano de Ciencias Sociales, p. 195-216, 2004a.

. Sociedade Civil, Espaços Públicos e a Construção Democrática no Brasil: Limites e Possibilidades. In: ___ Sociedade Civil e Espaços Públicos no Brasil. São Paulo: Paz e Terra, p. 279-301, 2002.

. Sociedade civil, participação e cidadania: de que estamos falando? In: MATO, D. (Coord.). Políticas de Ciudadania y sociedade civil en tiempos de globalización. Caracas: FACES, Universidad Central de Venezuela, p.95-110, 2004b.

; TEIXEIRA, A. C. C. The participation of civil society in Lula's government. Journal of Politics in Latin America, v. 6, n. 3, 2014, p. 39-66.

DINIZ, P. C. O. Da experimentação social ao "experimentalismo institucional”: trajetórias de relações entre Estado e sociedade civil. Experiências no semiárido. Tese. 237 p. Programa de Pós Graduação em Sociologia - Universidade Federal de Campina Grande, Universidade Federal da Paraíba, Campina Grande, 2007.

DINIZ, P. C. O. ; PIRAUX, M. Agroecologia e convivência com o semiárido: breves notas de uma longa trajetória de diálogo e interfaces. In: LIMA, J. R. T. de. (Org.) Agroecologia e movimentos sociais. Recife: Bagaço, p.147- 168, 2011a.

DINIZ, P. C. O.; PIRAUX, M. Das intervenções de combate à seca às ações de convivência com o semiárido: trajetória de 'experimentalismo institucional' no semiárido brasileiro. Cadernos de Estudos Sociais, v. 26, n.2, p. 227-238, jul/dez, 2011b.

DOSSIÊ FÓRUM SECA. FÓRUM PERNAMBUCANO DE ENFRENTAMENTO À PROBLEMÁTICA DA SECA. Este dossiê registra destaques dos primeiros passos dados pelo Fórum Seca, o início dessa nova história escrita com a luta e a sabedoria os homens e mulheres comprometidos com a emancipação dos trabalhadores rurais do nosso Nordeste. Recife, junho de 1991.

FAVERO, O. Uma pedagogia da participação popular: análise da prática educativa do MEB - Movimento de Educação de Base (1961/1966). Campinas, SP: Autores Associados, 2006. (Coleção Educação Contemporânea), 304 p.

GOHN, M. da G. Desafios dos movimentos sociais hoje no Brasil. SER social, Brasília, v. 15, n. 33, p. 261-384, jul/dez, 2013.

GRAMSCI, A. Cadernos do Cárcere. Volume 3. 3. ed. Rio de Janeiro, Civilização Brasileira, 2007.

I SEMINÁRIO PERNAMBUCANO, SECA, IMPLICAÇÕES POLÍTICAS E FORMAS DE ENFRENTAMENTO. Projeto tecnologias Alternativas o Centro Josué de Castro; Pólo Sindical de Serra Talhada, Comissão Pastoral da Terra; Grupo de Ecologia Humana da UFRPE; OXFAM. Camaragibe/PE, 27 a 30 de agosto de 1990. 
MALVEZZI, R. Semiárido: uma visão holística. Brasília: Confea, 2007. 140 p. (Pensar Brasil)

MULLER, P.; SUREL, Y. A análise das políticas públicas. 2.ed.Pelotas: EDUCAT, 2004. 156 p.

PASSADOR, C. S.; PASSADOR, J. L. Apontamentos sobre as políticas públicas de combate à seca no Brasil: cisternas e cidadania? Cadernos Gestão Pública e Cidadania, v.15, n. 56. p. 65-86, 2010.

RELATÓRIO HISTORICO DO FÓRUM SECA, 1989 a 1996. Recife, março, 1997.

SECA, UM PROBLEMA QUE TEM SOLUÇÃO: FÓRUM PERNAMBUCANO DE ENFRENTAMENTO À PROBLEMÁTICA DA SECA. Cartilha. Marcos Figueiredo (Org.). Recife, abril de 1995.

SIEBER, S. S.; GOMES, R. A. O plano municipal de convivência com o semiárido como instrumento discursivo: um estudo de caso no sertão de Pernambuco, Brasil. Sustentabilidade em Debate, v.7, p.226 - 238, 2016.

SIEBER, S. S.; GOMES, R. A. Entre novos paradigmas e velhas práticas: a convivência com o semiárido e a agricultura familiar no semiárido nordestino. Cronos (Natal Impresso), v.14, 2013, p. 171-189.

SILVA, M. K.; OLIVEIRA, G. de. L. A face oculta(da) dos movimentos sociais: trânsito institucional e intersecção Estado - Movimento - uma análise do movimento de economia solidária no Rio Grande do Sul. Sociologias, Porto Alegre, ano 13, n. 28, p. 86-124, set./dez., 2011.

SILVA, R. M. A. Entre o combate à seca e a convivência com o semiárido: transições paradigmáticas e sustentabilidade do desenvolvimento. 2006. 289 p. Tese. (Doutorado em Desenvolvimento Sustentável) - Universidade de Brasília, Brasília. 